\title{
The Academic-Industry Gap
}

\section{Dick Lundqvist, Bromma \\ (Swedish Royal Academy of Sciences)}

\begin{abstract}
Report on initiatives undertaken in Sweden to promote closer relations between institutes of physics and industry. The results of this experience were presented to the EPS Advisory Committee on Applied Physics and Physics in Industry where it was concluded that they were of international relevance. All countries suffer from the division between academic and industrial practice in physics, so that the failures and successes recorded in Sweden are of general significance.
\end{abstract}

In 1968, the section of the Royal Academy of Engineering Sciences (IVA) devoted to "fundamental and border sciences of technology", which is dominated by physicists from a wide variety of disciplines, decided to strengthen its promotion of physics in industry by setting up a permanent committee. The mandate given to this IVA Committee for Physics in Industry was to "assist in the development of the Swedish industry in the field of technical physics" by stimulating increased cooperation between industrial companies and the institutes of the Universities. It was expected that this would lead to new or neglected fields of physics research being indentified and then cultivated.

A first disappointment was the weak response that came from the efforts made to persuade physicists, having taken their degrees, to apply for posts in industry and also to encourage industry to be receptive to such candidates. No single reason could be found for this failure but it was clear that even at this level a barrier exists.

A second initiative met with greater success only on the surface. The Committee instituted a series of "contact days" at the Universities when the physics institutes gave lectures and demonstrations to people invited from appropriate industries. These contact days stimulated considerable interest, so much so that it was soon concluded that the Universities themselves should take over the arrangements as a regular activity. The initially high interest, however, gradually decreased and very little of lasting value seems to have been gained. In retrospect, we can appreciate that it was unrealistic to hope that by this method we could diminish the growing distance between pure science or technical science and industry. Harsh reality has revealed that it was a far too simple approach, to bring people together as passing acquaintances just for one day.

A third method the Committee tried, was to arrange symposia or contact conferences on selected topics. The idea was to call attention to those physical subjects that were emerging from scientific or technical research and which seemingly were approaching a stage of application, but were still too little known by industry.

An extensive search was undertaken to select topics and evaluate their industrial potential following which a number of symposia were arranged, some with programmes covering two to three days. It was emphasized that the presentations (lectures) given should be so written and performed, that they would stimulate discussions and establish more permanent cooperation between the scientists and the industry representatives. Topics treated included:

Noise mechanics and prevention (sources)

\section{Surface phenomena}

Optronics

Ultra high pressure methods and products

New measuring methods - New measuring problems

Generally these symposia elicited a very positive response, especially the last mentioned, which was arranged as a work-shop Presentations were made of a maximum of six minutes and these started lively discussions in the small working groups. Participants expressed great satisfaction with the system and asked for others to be organized.

So far, so good. But when a thorough analysis was made afterwards, of how many new contacts had been established as a result of the discussions, we were very disappointed. Just one really valuable contact had been made and this was between two industries.

The Committee also supported or sponsored other activities with related purposes initiated by other organizations. In all cases we are obliged to record the fact that the feedback was negligible.

\section{Efforts of the Swedish Physical Society}

A Section for the Industrial Application of Physics was set up by the Swedish Physical Society for much the same purpose as the IVA Committee, except that it was to take care of the ambitions, interests and ideas emanating from its own members, who belong mainly to university institutes of physics. At the start there was a considerable, even if perhaps naive, enthusiasm about this new channel that would lead from the physics laboratories to industry. Very soon it turned out, however, that the beautiful idea was unrealistic, mainly for two reasons:

The individual members approached by written inquiry and asked to contribute with tangible proposals or activities failed to respond.

Lack of appropriate funds made it impossible to invite members to participate in working groups or conferences at which it might have been possible to awaken their willingness to take part in projects or other activities.

In 1976 the Swedish Physical Society devoted its yearly conference to the problems of physics education and physics transfer to industry, the Section Board taking an active part in its preparation. At the lectures and the following discussions much enthusiasm was declared for various schemes designed to build up a system of intimate contacts between science and industry. But nothing materialized. Then again different physics institutes were approached to give their ideas on what could be the next physical discovery to be exploited by industry. The answers, though ambitious, did not reveal anything that the appropriate industries had not known about long since.

We also learned, that all those physics institutes, that had a living interest in the technical properties of the systems they were investigating, and which wanted contacts with industry, already had made such contacts a 
long time ago. Those institutions on the other hand, where there was no tradition of industrial contacts, often demonstrated a complete lack of interest. Individuals inside them trying to establish contacts for themselves and to induce their colleagues to do the same were regarded with suspicion.

\section{Positive Reactions}

After recording these rather negative results, it is a relief to be able to report now on the more promising results from the efforts made.

Concluding that part of the difficulty of establishing working contacts between institutes of physics and industry might depend on the form of education current in physics, an attempt was made to study if such difficulties could be reduced by holding a combination of courses or seminars together with representatives of industry, and by sending teachers of physics to work in industry.

The secretary of the Section, Bengt Kjöllerström of the University of Lund, who personally made assiduous efforts to bridge the gap between a theoretical institute of physics and industry was the first to go for a one year working period to the Swedish car company Volvo. The experience seemed to be rewarding for both parties.

Later the Swedish Board for Universities and Colleges financed a four week practice period for 17 professors of physics in different industries. The result was so encouraging that it is being repeated in improved forms and for extended periods of time.

\section{General Conclusions}

From all these activities we have learned a lot about the character and dimension of the problem.
In most industries, physics certainly has important functions, but these functions are always intimately bound up with a great number of other equally important functions and must fit into the companies' production programmes. (A proposed new product has to be compared for profitability with other existing or potential products as regards both production and marketing capacities. The level of technical improvment must also be substantial if it is to replace an established product.) It will never be possible to convince a company that it should replace one product by another only because of its new and superior physical performance. Decision processes in industry are complex.

On the other hand, many industries feel a strong need for a deeper knowledge of the physics behind some of their processes. They may want new detectors or other devices and better measuring methods. For that reason they will sometimes approach the institutes of physics and ask them for help in solving their problems. Then they will often find, that there is a bad fit between their wishes and the institutes' programmes and resources. Also it happens that large industries have far better equipment than the Universities. A more severe obstacle may be, however, that the pattern of interest and of working habits of the competent scientists inhibits cooperation. Academic decision processes are also complex.

The only way to overcome these basic hindrances is, as far as we can see, to establish person to person contacts with intensive mutual exchange of information (to "sell" the problems) and of such long duration that new patterns of interest and respect can develop. The industry man must learn the best way to use the physicist in his project. The physicist must learn to understand the complex conditions to be satisfied in an industrial project and discover the deep satisfaction he can feel when he has made his contribution to a successful development.

IVA has accepted this lesson and dissolved its Physics in Industry Committee and replaced it by a Committee for Physical-Technical Systems, the name indicating a more pronounced project character. It is intended that it should organize physicists and engineers more efficiently in a common attack on important problems.

The other promising technique already mentioned is to give University teachers the opportunity of working for a fairly long time in industry, giving them insight into industrial problems and allowing industrial staff to become familiar with physicists as collaborators. Later on, this practice could perhaps be extended to students as part of their training.

\section{Associate Members}

New Director General of ESA from 15 May, 1980 is Mr. E. Quistgaard, currently Director of Odense-Lindö Stalskibsvaerft, Denmark.

CERN has announced that its new Director-General from 1, January, 1981 will be $\mathrm{H}$. Schopper, presently Director of DESY, Hamburg.

\section{Member Societies}

New President of the Finnish Physical Society is Prof. M. Krusius of the University of Turku.

New President of the German Physical Society is Prof. H. Rollnik of the University of Bonn.

\section{New Members of the European Physical Society}

CATEGORY 4A

J.P. Mercier, Louvain-la-Neuve, B

T. Nagarajan, Guindy, Madras, India

CATEGORY $4 \mathrm{C}$

Austrian Physical Society

D. Bäuerle, Linz/Auhof

M. Steuer, CERN, Geneva, CH

Belgian Physical Society :

J. Lemonne, Brussels

Danish Physical Society

Anders Lindgard, Copenhagen

Eötvös Lorand Physical Society : Istvan Dészi, Budapest

The Institute of Physics :

C.A. Ramm, Black Rock, Victoria, Aus.
German Physical Society :

H. Bunge, Clausthal-Zellerfeld

A. Campo-Cabal, Würzburg

H.-J. Daams, Aachen

B. Fricke, Kassel

E. Gmelin, Stuttgart

A. Hess, Offenbach

J. Hönigschmid, Konstanz

J. Janes, Freiburg

J. Janes, Freiburg
H. Keller, Ludwigshafen

$M$. Lehmann, Erlangen

N. Melcher, Düsseldorf

E. Rathske, Bonn

H. Schramm, Bruchköbel

H. Teichmann, Kreizwertheim

C.-P. Troch, Hamburg

P. Tuerkes, Lichtenfels

G.H. Wolf, Jülich

Hellenic Physical Society :

L. Resvanis, Athens

French Physical Society :

B. Julia, Paris
Italian Physical Society :

C. Calandra, Modena

F. Menzinger, Rome

R. Pallavicini, Florence

R. Pettorino, Naples

The Netherlands' Physical Society :

J. de Hosson, Groningen

L. Klieb, Groningen

Norwegian Physical Society :

Øisten Elgarøy, Blindern

K. Myklebost, Bergen

O. Steinsvoll, Lillestrom

Polish Physical Society :

A. Kotanski, Krakow

S. Majewski, Warsaw

Portuguese Physical Society :

M.F. Laranjeira, Lisbon

A.M.C. Moutinho, Lisbon
Swedish Physical Society :

T. Akesson, CERN, Geneva, CH

S. Bjarman, Uppsala

N.O. Elander, Stockholm

E. Figueroa-Karlström, Gothenburg

K.R. Jakobson, Gothenburg

A. Johansson, Växjổ

S. Lindahl, Uppsala

K. Minnberg, Älvsjö

N.G. Nilsson, Täby

E. Orre, Landeryd

S. Selander, Uppsala

S. Tornkvist, Bahrain

J. Weitman, Nyköping

Swiss Physical Society :

A. Baratoff, Rüschlikon

B. Jenny, Zürich

ASSOCIATE MEMBER

Fachinformationszentrum Energie

Physik Mathematik GmbH

Federal Republic of Germany 